\title{
Hypoxic Proliferation of Osteosarcoma Cells Depends on Arginase II
}

\author{
Bhuvana A. Setty Yi Jin Peter J. Houghton Nicholas D. Yeager Thomas G. Gross \\ Leif D. Nelin \\ Division of Pediatric Hematology/Oncology/BMT, Nationwide Children's Hospital; Center for Perinatal \\ Research, The Research Institute at Nationwide Children's Hospital; and Department of Pediatrics, The \\ Ohio State University, Columbus, USA
}

\section{Key Words}

Arginine $\cdot$ Arginase $\bullet$ Osteosarcoma $•$ Proliferation

\begin{abstract}
Background/Aims: Despite significant advancements in the diagnosis and treatment of osteosarcoma, the overall survival has remained relatively unchanged for over two decades. Hypoxic conditions have been demonstrated in solid tumors and are associated with increased cell proliferation and angiogenesis. L-arginine metabolism by arginase produces L-ornithine, the precursor for polyamine and proline synthesis required for cellular proliferation. We hypothesized that hypoxia would increase cellular proliferation via arginase induction in human osteosarcoma cell lines. Methods: We utilized a variety of approaches to examine the role of arginase II in hypoxic $\left(1 \% \mathrm{O}_{2}, 5 \% \mathrm{CO}_{2}\right)$ cellular proliferation. Results: Arginase II mRNA and protein levels were significantly increased in osteosarcoma cells exposed to hypoxia for 48 hours. There were twice as many viable cells following 48 hours of hypoxia than following 48 hours of normoxia $\left(21 \% \mathrm{O}_{2}, 5 \% \mathrm{CO}_{2}\right)$. The addition of difluoromethylornithine (DFMO), a putative arginase inhibitor, prevented hypoxia-induced proliferation. Transfection of small interfering RNAs (siRNA) targeting arginase II resulted in knockdown of arginase II protein levels and prevented hypoxia-induced cellular proliferation. Conclusions: These data support our hypothesis that hypoxia increases proliferation of osteosarcoma cells in an arginase II-dependent manner. We speculate that arginase II may represent a therapeutic target in osteosarcoma.

\section{Introduction}

Osteosarcoma is the most common malignant bone tumor in children and young adults with approximately 900 new cases diagnosed annually in the United States. The most common primary sites are the distal femur, proximal tibia and proximal humerus. Metastatic lesions are most commonly seen in the lung, but can occur in other bones and soft tissues as well. It is a highly aggressive neoplasm that is composed of spindle cells producing osteoid 


\section{Cellular Physiology Cell Physiol Biochem 2016;39:802-813 \begin{tabular}{l|l|l}
\hline and Biochemistry 10.1159/000447790 & $\begin{array}{l}\text { C) } 2016 \text { The Author(s). Published by S. Karger AG, Basel } \\
\text { www.karger.com/cpb }\end{array}$ \\
\hline
\end{tabular} \\ Setty et al.: Arginase and Osteosarcoma Cells}

or immature bone. The treatment of osteosarcoma has not significantly changed in the last 20 years. Standard therapy consists of a combination of chemotherapy and aggressive surgical resection of the primary site and metastatic sites. Unfortunately, the improvement in outcomes seen for many other cancers has not been demonstrated in osteosarcoma, with $50 \%-60 \%$ five-year disease free survival rates for patients with localized disease and less than $20 \%$ for those with metastasis at diagnosis. There is an urgent need for new and more effective therapies for osteosarcoma to enable positive outcomes for these patients $[1,2]$.

Normal cells and cancer cells have been shown to activate signaling pathways to induce cell proliferation, angiogenesis, and apoptosis under hypoxic conditions [3]. Hypoxic conditions are seen in solid tumors despite hypervascularization due to an imbalance between the rates of tumor cell proliferation, new endothelial cell formation, and disorganized vascular supply $[4,5]$. Hypoxia has been shown to affect the L-arginine metabolic pathway in various types of cells, including smooth muscle cells and endothelial cells [6, 7]. L-arginine is the substrate for arginase, of which two isoforms have been described $[8,9]$. Arginase I is a cytosolic enzyme that is highly expressed in the liver, while arginase II is a mitochondrial protein that is not expressed in the liver [10]. Both isoforms of arginase are expressed in various cell types throughout the body. The metabolism of L-arginine by arginase leads to the production of L-ornithine and urea, which is the first step in polyamine and proline synthesis. Polyamines and proline are critical for cell proliferation, differentiation, tissue repair, and growth [11, 12]. Arginine influences the growth of tumor cells, and dietary restriction of arginine has been shown to inhibit metastatic disease [13]. Given that the core of solid tumors like osteosarcoma can be hypoxic and the relation between hypoxia and arginase in other cell types, we hypothesized that hypoxia would result in arginase-dependent proliferation of osteosarcoma cells

\section{Materials and Methods}

\section{Cell Culture}

SaOS-2 cells were obtained from ATCC (Manassas, VA) and OS-17 xenograft cells from a patient specimen were provided by Dr. Houghton's laboratory at the Research Institute of Nationwide Children's Hospital. SaOS-2 cells were cultured in McCoy's 5A Medium containing 10\% fetal bovine serum. OS-17 cells were cultured in Dulbecco's Modified Eagle Medium (DMEM) containing 10\% fetal bovine serum (Mediatech, Manassas, VA). The cells were grown to approximately 80-90\% confluence and washed with PBS. $10 \mathrm{ml}$ of fresh media was placed on the cells, and they were incubated at $37^{\circ} \mathrm{C}$ in either $5 \% \mathrm{CO}_{2}$, balance air (normoxia) or $5 \% \mathrm{CO}_{2}, 1 \% \mathrm{O}_{2}$ balance $\mathrm{N}_{2}$ (hypoxia) for 24 hours.

\section{Protein Isolation}

Cells were washed twice with ice-cold HEPES buffer and $200 \mu \mathrm{l}$ lysis buffer $(0.2 \mathrm{M} \mathrm{NaOH}, 0.2 \%$ SDS with the following added to each $\mathrm{ml} 30$ minutes before use: $1 \mu \mathrm{g}$ aprotinin, $1 \mu \mathrm{g}$ leupeptin, and $1 \mu \mathrm{g}$ phenylmethylsulfonyl fluoride; all from Sigma, St Louis, MO) were placed on the cells. The plates were scraped, pipetted into sterile centrifuge tubes and placed on ice for 30 minutes. The cell lysates were centrifuged at $12,000 \mathrm{~g}$ for 10 minutes. The supernatant was stored in $1.5 \mathrm{ml}$ tubes at $-80^{\circ} \mathrm{C}$. Total protein concentration was determined by the Bradford method (BioRad, Hercules, CA).

\section{Western blot analysis}

The cell lysates were assayed for levels of arginase I and arginase II protein using immunoblot analysis as previously described [14]. Aliquots of cell lysate were diluted with $10 \mu \mathrm{l}$ SDS sample buffer, $4 \mu \mathrm{l}$ reducing agent, and appropriate amounts of deionized water. The samples were then heated to $80^{\circ} \mathrm{C}$ for 10 minutes, and then separated using SDS-PAGE gel electrophoresis. The proteins were transferred to PVDF membranes, and blocked overnight in TBS with $0.1 \%$ Tween (TBS-T) containing 5\% skim milk. The following day the membranes were washed 4 times with TBS-T and then incubated with primary antibody against arginase I or arginase II (both 1:500; Santa Cruz Biotechnology, Santa Cruz, CA). The membranes were then washed another 4 times with TBS-T, and incubated with goat anti-rabbit IgG HRP conjugated secondary antibody 


\section{Cellular Physiology Cell Physiol Biochem 2016;39:802-813 \begin{tabular}{l|l|l} 
and Biochemistry & DOI: 10.1159/000447790 & $\begin{array}{l}\text { C } 2016 \text { The Author(s). Published by S. Karger AG, Basel } \\
\text { www.karger.com/cpb }\end{array}$
\end{tabular} \\ Setty et al.: Arginase and Osteosarcoma Cells}

(1:10,000; Bio-Rad) for 1 hour and then washed 4 times with TBS-T. The bands for total arginase I or arginase II were visualized using chemiluminescence (Amersham ECL plus Reagent, Piscataway, NJ) and quantified using densitometry (Total Lab gel analysis; Biosystematica, Mountain Hall, Wales, UK). To control for protein loading, the blots were stripped and re-probed for $\beta$-actin using a monoclonal antibody $(1: 5,000$; Abcam, Cambridge, MA).

\section{Viable cell number}

To determine viable cell numbers, 5,000 cells were plated into each well of a 6-well plate. The appropriate treatments were included in the media and the cells were placed in either hypoxia or normoxia for a period of 24 or 48 hours. Depending on the experimental protocol, either $100 \mu \mathrm{M}$ or 1 mM $\alpha$-difluoromethylornithine (DFMO, Cayman Chemical, Ann Arbor, MI) was included in the respective medium, such that treatments were added at time 0 , the start of the exposure to either normoxia or hypoxia, of the given experiment. We chose these concentrations of DFMO based on previous studies demonstrating that 1 to $400 \mu \mathrm{M}$ can inhibit arginase activity in a variety of cell types [15-17]. In additional studies $100 \mu \mathrm{M}$ S-(2-boronoethyl)-L-cysteine (BEC, Cayman Chemical, Ann Arbor, MI) or $10 \mu \mathrm{M} \mathrm{N}^{\omega}$-hydroxy-arginine (NOHA, Cayman Chemical) or their respective vehicle were used, we chose these concentrations of BEC and NOHA based on our previous experience [7]. At the end of the experimental protocol, the cells were removed from the incubator and plates were washed 3 times with PBS. After the final wash, $1 \mathrm{ml}$ of trypsin was added to each well. The plates were incubated for $\sim 3$ minutes followed by the addition of $2 \mathrm{ml}$ trypsin neutralizing solution. The cells from each well were placed in $15 \mathrm{ml}$ conical tubes. The cells were centrifuged for $5 \mathrm{~min}$ at $1220 \mathrm{xg}$ at $4^{\circ} \mathrm{C}$. The supernatant was discarded and the cells were re-suspended in $1 \mathrm{ml}$ of medium. The cells were mixed 1:1 with trypan blue and viable cells were counted using a hemocytometer.

\section{RNA isolation and Real time PCR}

RNA was isolated from cells using Trizol (Invitrogen, Carlsbad, CA). DNase treatment was performed on all samples using RNase-free DNase (Super Array, SA Biosciences, Frederick, MD) followed by reverse transcription (Promega, Madison, WI) and then analysis of cDNA by Real time PCR using SYBR Green jumpstart Taq (Sigma). Primers were ordered from IDT (Integrated DNA Technologies Coralville, IA) using the following sequences for human Arginase I forward primer: 5 'TTGGCAATTGGAAG-CATCTCTGGC 3'; reverse primers: 5' TCCACTTGTGGTTGTCAGTGGAGT 3'. Arginase II was amplified using the forward primer: 5' TTAGCAGAGCTGTGT-CAGATGGCT 3' and the reverse primer: 5' GGGCATCAACCCA-GACAACACAAA 3'. 18S was amplified using the forward primer (5' CCAGAGCGAAAGCATTTGCCAAGA 3') and the reverse primer (5' TCGGCATCGTTTATGGTCGGAACT 3'). For each reaction, negative controls containing reaction mixture and primers without cDNA were performed to verify that primers and reaction mixtures were free of template contamination. Relative arginase amounts were normalized to $18 \mathrm{~S}$ expression using the $\Delta \Delta \mathrm{CT}$ method [18]. All samples were analyzed in duplicate. Data are shown as fold-change relative to normoxia-exposed control cells at each respective time point.

Urea assay

OS-2 cells were plated in $60 \mathrm{~mm}$ plates and grown to $80-90 \%$ confluence. Cells were washed and had $4 \mathrm{ml}$ of media containing $1 \mathrm{mM} \mathrm{L}$-arginine and $1 \mathrm{mM} \mathrm{MnCl}_{2}$, and placed in either normoxia or hypoxia. After 48 hours the media was collected and assayed for urea concentration colorimetrically as previously described $[6,7]$.

\section{Transfection of Arginase II siRNA}

Transfection of arginase II-small interfering RNAs (siRNA) was performed as previously described [6, $7,14]$ to determine the effects of arginase II gene silencing on SaOS-2 and OS-17 proliferation. We obtained siRNA against human arginase II from Dharmacon as a mixture of 4 different siRNA against arginase II in a single reagent (ON-TARGETplus arginase II siRNA, catalogue number L-009454-01-0005). DharmaFECT 1 transfection reagent (Thermo Fisher Scientific, Lafayette, CO) was used according to manufacturer's protocol. Briefly, in $1.5 \mathrm{ml}$ centrifuge tubes, $100 \mu \mathrm{l}$ of $2 \mu \mathrm{M}$ siRNA, arginase II-siRNA (Thermo Fisher Scientific), or non-targeting scramble siRNA (Thermo Fisher Scientific) was mixed with $100 \mu$ of smooth muscle basal medium (Lonza), vortexed, and incubated at room temperature for 5 minutes. The DharmaFECT 1 transfection reagent was diluted 1:100 (total volume of $200 \mu \mathrm{L}$ ) and incubated at room temperature for 


\section{Cellular Physiology Cell Physiol Biochem 2016;39:802-813 \\ \begin{tabular}{l|l|l|}
\hline DOI: 10.1159/000447790 & $\begin{array}{l}\text { (c) 2016 The Author(s). Published by S. Karger AG, Basel } \\
\text { www.karger.com/cpb }\end{array}$
\end{tabular} \\ Setty et al.: Arginase and Osteosarcoma Cells}

5 minutes. The transfection reagent was then added to each sample of siRNA, mixed and incubated at room temperature for 20 minutes. McCoy 5A medium modified or DMEM was then added to each tube for a total volume of $1 \mathrm{ml}$. For the vehicle-treated SaOS-2 and OS-17, $\mathrm{DDH}_{2} 0$ was used in place of siRNA.

SaOS-2 or OS-17 cells were grown to $\sim 70 \%$ confluence in six-well plates, and then washed with PBS. Fresh media $(1 \mathrm{ml})+$ siRNA-DharmaFECT reagent mixture $(1 \mathrm{ml})$ were placed in each well of a six-well plate. SaOS-2 and OS-17 were incubated in normoxia for another 24 hours. Transfected SaOS-2 and OS-17 were used in experiments and incubated in either normoxia or hypoxia for 48 hours. Protein was harvested for Western blot analysis or cells were prepared and counted for proliferation assay as described above.

\section{Statistical analysis}

Data are presented as mean \pm SE. When comparing 2 groups a t-test was utilized. When comparing more than 2 groups, a one-way ANOVA was used with Student-Newman-Keuls post hoc tests to identify differences between groups. Differences were considered significant when $p<0.05$.

\section{Results}

Hypoxia increased arginase II expression in osteosarcoma cells

SaOS- 2 or OS-17 cells were grown to approximately $90 \%$ confluence and incubated in either normoxia or hypoxia for 24 hours to determine the effects of hypoxia on arginase mRNA expression. RNA was harvested, and arginase I and arginase II mRNA expression was determined by real-time PCR. There was no significant difference in arginase I mRNA levels between normoxic and hypoxic SaOS- 2 cells. There were $\sim 4$ fold greater arginase II mRNA levels in hypoxic SaOS-2 cells than in normoxic SaOS- 2 cells ( $p=0.018)$. In OS-17 cells there was a tendency $(p=0.055)$ toward greater arginase I mRNA levels following hypoxia than following normoxia. On the other hand, there was a robust ( $\sim 9$ fold) hypoxia-induced increase in arginase II mRNA levels in OS-17 cells ( $p=0.009)$.

The effects of hypoxia on arginase protein expression on SaOS-2 and OS-17 cells were determined by growing cells to $80-90 \%$ confluence and incubating in hypoxia or normoxia for 24 hours. Protein was harvested and expression of arginase I and arginase II was determined using Western blot analysis. There were no significant differences in the protein levels for arginase I in SaOS-2 or OS-17 cells exposed to normoxia or hypoxia (data not shown). There was a $\sim 2$ fold greater arginase II protein level in the hypoxic SaOS-2 cells

Fig. 1. Arginase II protein levels were greater in hypoxic cells than in normoxic cells. Cells $(n=6)$ were incubated for 24 hours in either normoxia or hypoxia and protein harvested for western blot evaluation of arginase II. (A) A typical western blot for Arginase II from SaOS-2 cells. (B) A typical western blot for Arginase II from OS-17 cells. (C) Densitometric quantifica-

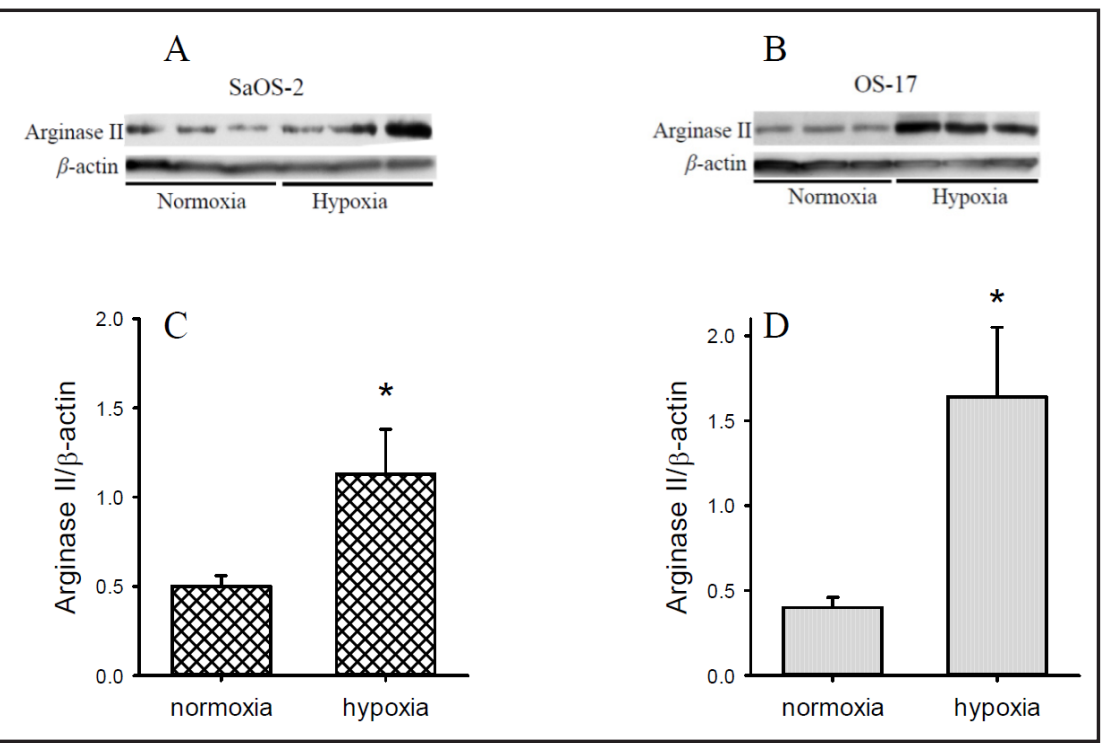
tion of Arginase II protein levels normalized to $\beta$-actin in SaOS-2 cells. (D) Densitometric quantification of Arginase II protein levels normalized to $\beta$-actin in OS-17 cells. * hypoxia different from normoxia, $p<0.05$. 
Fig. 2. The hypoxia-induced increases in arginase II mRNA and/or protein levels were not caused by changes in stability. (A) Arginase 2 mRNA half-life during normoxia (grey triangles) and hypoxia (closed circles). OS-17 cells ( $\mathrm{n}=3$ in each condition) were incubated in normoxia or hypoxia for 24 hours and then treated with actinomycin D and RNA was harvested at $0,2,4,8,12$, and 24 hours for qPCR determination of arginase II mRNA levels. The mean half-life for arginase II mRNA from the exponential fit of the data was 5.6 hours in normoxia (dashed line) and 5.1 hours in hypoxia (solid line). (B) Arginase II protein half-life during normoxia (open circles) and hypoxia (closed circles). OS-17 cells ( $\mathrm{n}=3$ in each condition) were incubated in normoxia or hypoxia for 24 hours and then treated with cycloheximide and protein harvested at $0,2,4,8,12,24,48$ and 72 hours for western blotting for arginase II and $\beta$-actin. The mean half-life for arginase II protein from the exponential fit of the data was 11.9 hours in normoxia (dashed line) and 11.1 hours in hypoxia (solid line).

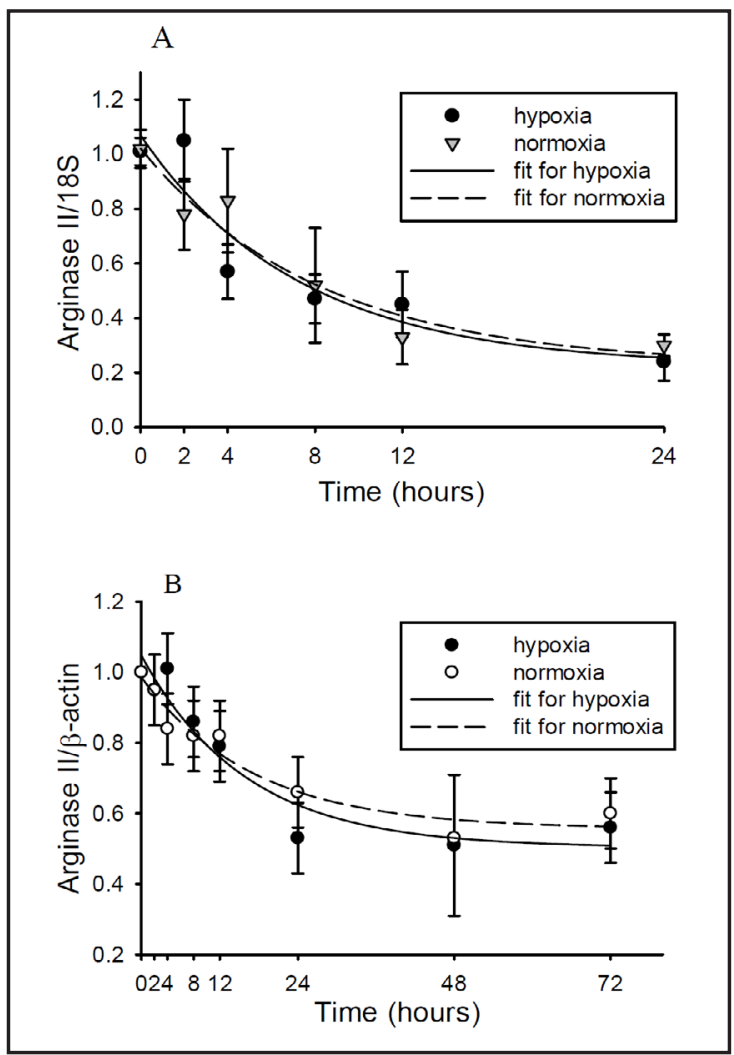

Fig. 3. The putative arginase inhibitor DFMO prevented hypoxia-induced proliferation in both SaOS-2 $(n=6)$ and OS-17 $(n=6)$ cells. 5,000 cells were seeded in each well of a 6 well plate, cells were treated with vehicle (control, black bars) or DFMO (grey bars) and incubated for 48 hours in normoxia or hypoxia. The number of viable cells was determined using trypan blue exclusion. * hypoxic control different from normoxic control, $p<$ 0.005. \# hypoxic DFMO treated different from hypoxic control, $p<0.001$.

than in the normoxic SaOS-2 cells (Fig. $1 \mathrm{~A} \& 1 \mathrm{C})$. We found a significant increase in urea production in SaOS-2 cells $(3.15 \pm 0.30$ $\mu$ mole $/ \mathrm{mg}$ protein in normoxic cells and $4.21 \pm 0.17 \mu \mathrm{mole} / \mathrm{mg}$ protein in hypoxic cells, $\mathrm{p}<0.05$ ). There was also a $\sim 5$ fold greater arginase II protein level in hypoxic OS-17 cells than in normoxic OS-17 cells (Fig. 1B\&1D).

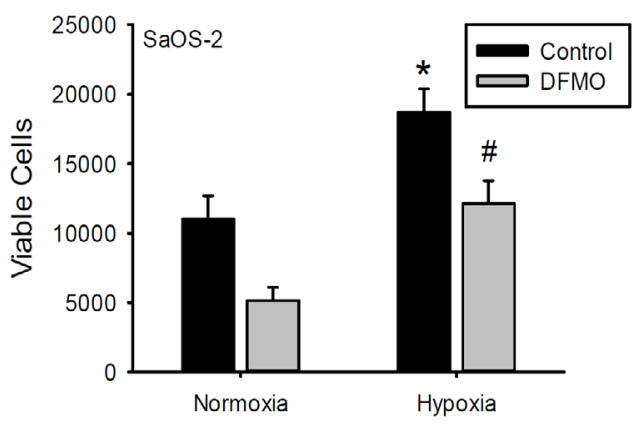

To determine if the hypoxia-induced changes in arginase II mRNA and/or protein levels were due to changes in either mRNA and/or protein stability we utilized actinomycin D to stop mRNA production and cycloheximide to stop protein production in OS-17 cells incubated in either normoxia or hypoxia. OS-17 cells were incubated in either normoxia or hypoxia for 24 hours and then treated with actinomycin D and at $0,2,4,8,12$, and 24 hours RNA was harvested for real-time PCR determination of arginase II and 18S. There 


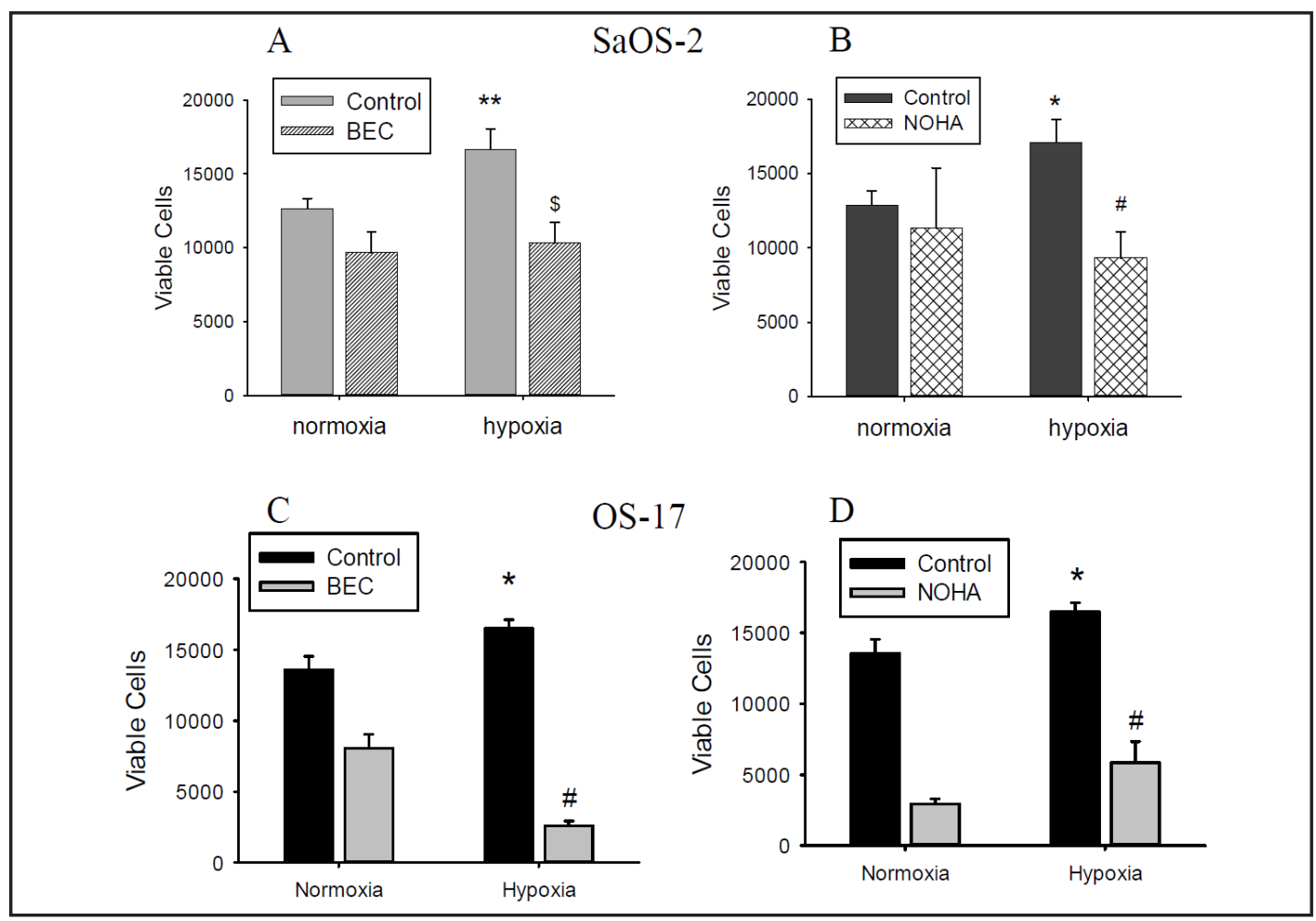

Fig. 4. The putative arginase inhibitors BEC and NOHA also prevented hypoxia-induced proliferation in SaOS- 2 cells (A and B) and in OS-17 cells (C and D). SaOS-2 or OS-17 cells $(5,000)$ were seeded in each well of a 6 well plate and treated with either vehicle or inhibitor, and incubated for 48 hours in either normoxia or hypoxia. The number of viable cells was determined using trypan blue exclusion. (A) SaOS-2 cells ( $\mathrm{n}=6$ in each condition) treated with either vehicle (grey bar) or $100 \mu \mathrm{M} \mathrm{BEC} \mathrm{(cross-hatched} \mathrm{bar).} \mathrm{**} \mathrm{hypoxic} \mathrm{control}$ different from normoxic control, $\mathrm{p}<0.01$; \$ hypoxic BEC different from hypoxic control, $\mathrm{p}<0.005$. (B) SaOS2 cells ( $n=3-9$ in each condition) treated with either vehicle (dark grey bar) or $10 \mu \mathrm{M}$ NOHA (cross-hatched bars). (C) OS-17 cells ( $n=3-4$ in each condition) treated with either vehicle of $100 \mu \mathrm{M}$ BEC. D) OS-17 cells ( $n=3-4$ in each condition) treated with either vehicle or $10 \mu \mathrm{M}$ NOHA. * hypoxic control different from normoxic control, $\mathrm{p}<0.05$; \# hypoxic BEC different from hypoxic control, $\mathrm{p}<0.05$.

was no difference in the arginase II mRNA half-life in normoxia or hypoxia (Fig. 2A). OS17 cells were incubated in either normoxia or hypoxia for 24 hours and then treated with cycloheximinde and at $0,2,4,8,12,24,48$ and 72 hours protein was harvested for western blot determination of arginase II and $\beta$-actin. There was no difference in the arginase II protein half-life in normoxia or hypoxia (Fig. 2B).

\section{Hypoxia increased proliferation of osteosarcoma cells}

Proliferation of SaOS-2 and OS-17 cells exposed to either normoxia or hypoxia was determined by counting viable cells using trypan blue exclusion. 5,000 cells were seeded per well on a 6-well plate and incubated in either normoxia or hypoxia for 48 hours. Incubation in hypoxia for 48 hours resulted in approximately twice as many viable SaOS-2 cells compared to incubation in normoxia for 48 hours $(9,667 \pm 1,085$ viable cells normoxia versus 16,667 $\pm 1,333$ viable cells hypoxia, $\mathrm{p}<0.005$ ). A similar hypoxia-induced increase in viable cell numbers was found in the OS-17 cells $(7,333 \pm 667$ viable cells normoxia versus $12,333 \pm$ 954 viable cells hypoxia, $\mathrm{p}<0.005$ ).

Arginase inhibition prevented hypoxia-induced proliferation

To determine the role of arginase activity in hypoxia-induced osteosarcoma cell proliferation, the putative small molecule arginase inhibitor DFMO was used. We found that 


\section{Cellular Physiology Cell Physiol Biochem 2016;39:802-813 \begin{tabular}{ll|l} 
DOI: 10.1159/000447790 & $\begin{array}{l}\text { O 2016 The Author(s). Published by S. Karger AG, Basel } \\
\text { wwww.karger.com/cpb }\end{array}$
\end{tabular} \\ Setty et al.: Arginase and Osteosarcoma Cells}

Fig. 5. Transfection with siRNA against arginase II prevented hypoxia-induced proliferation in both SaOS-2 and OS-17 cells. Cells were transfected with siRNA against arginase II or scramble siRNA for 24 hours, the cells were then washed and placed in either normoxia or hypoxia for 48 hours. (A) Typical western blot demonstrating knock-down of arginase II using siRNA against arginase II in SaOS- 2 cells. (B) Viable cells numbers in SaOS-2 cells $(\mathrm{n}=3$ in each group and exposure) that were either non-transfected (control or C), scramble siRNA transfected (scramble or SC), or arginase II siRNA transfected (argII or siR) following 48 hours of exposure to either normoxia (black bars) or hypoxia (grey bars). * hypoxia different from normoxic control cells, $p<$ 0.05. \# hypoxic argII siRNA different from hypoxic controls or hypoxic scramble, $p<0.005$. (C) Typical western blot demonstrating knock-down of arginase II using siRNA against arginase II in OS-17 cells. (D) Viable cells numbers in OS-17 cells $(n=6$ in each group and exposure) that were either non-transfected (control or C), scramble siRNA transfected (scramble or SC), or arginase II siRNA transfected (argII or siR) after 48 hours in normoxia (black bars) or hypoxia (grey bars). * hypoxia different from normoxic control cells, $p<0.05$. \# hypoxic argII siRNA different from hypoxic controls or hypoxic scramble, $p<0.01$.

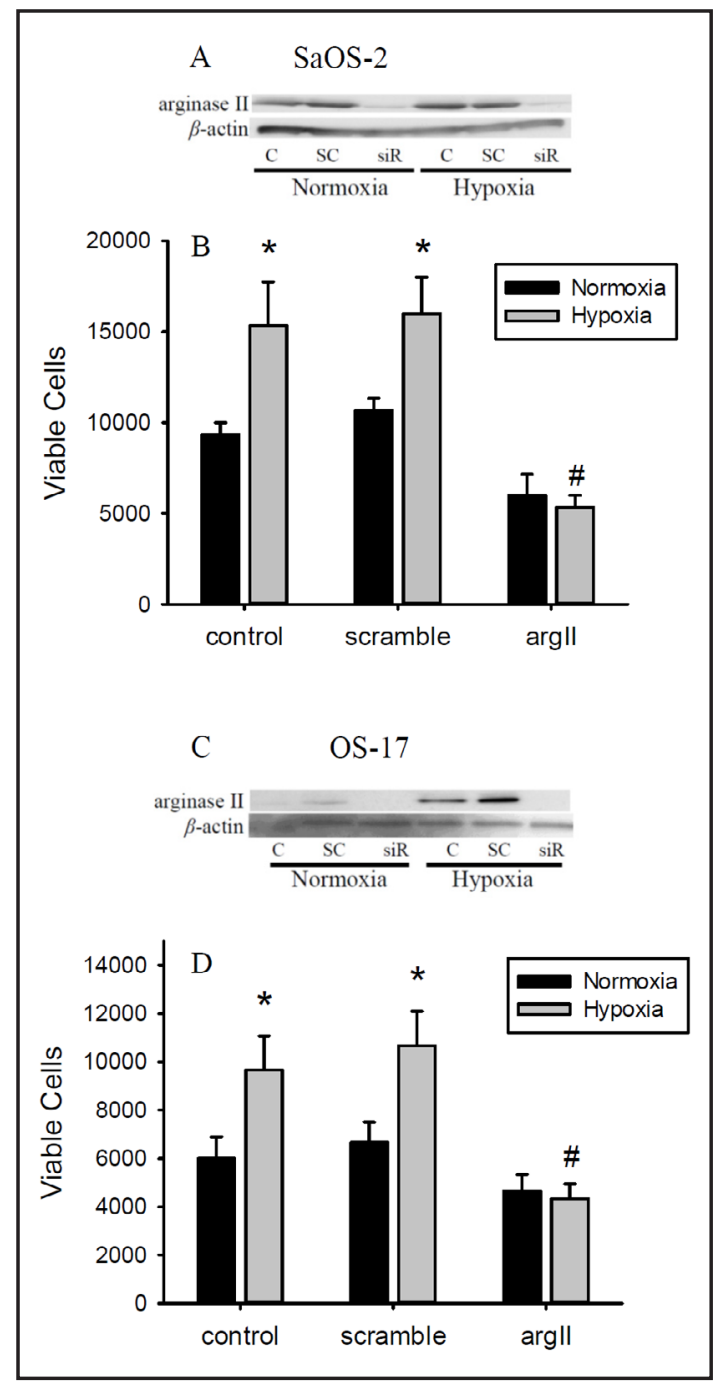

DFMO at $100 \mu \mathrm{M}$ decreased hypoxia-induced urea production by $48 \pm 21 \%(\mathrm{p}<0.05)$ in SaOS2 cells. SaOS-2 and OS-17 cells were seeded on a 6-well plate at 5,000 cells per well. Vehicle or DFMO was added to achieve a concentration of $100 \mu \mathrm{M}$ and the cells were incubated in either normoxia or hypoxia for 48 hours. Viable cell number was determined using trypan blue exclusion. The hypoxia-induced increase in viable cell numbers in both SaOS-2 and OS17 cells was completely prevented by DFMO (Fig. 3). Although, the mean numbers of viable cells tended to be lower in the normoxic DFMO treated cells than in the normoxic control cells, there was no significant difference between the groups (Fig. 3). Similar results were seen when $1 \mathrm{mM}$ concentration of DFMO was used. In SaOS- 2 cells there were 12,000 $\pm 1,033$ viable cells in control conditions, 8,667 $\pm 1,112$ viable cells in control $+1 \mathrm{mM}$ DFMO, 18,000 $\pm 1,713$ viable cells in hypoxia (different from control, $p<0.005$ ), and 8,667 \pm 989 viable cells in hypoxia $+1 \mathrm{mM}$ DFMO (different from hypoxia, $\mathrm{p}<0.001$ ). Similar results were found in OS- 17 cells 5,667 \pm 615 viable cells normoxia + vehicle; $4,000 \pm 516$ viable cells normoxia $+1 \mathrm{mM}$ DFMO; 10,000 \pm 516 viable cells hypoxia (different from normoxia, $\mathrm{p}<0.001$ ); and $5,6667 \pm 614$ viable cells hypoxia +1 mM DFMO (different from hypoxia + vehicle, $p<0.001$ ).

To examine other small molecule inhibitors of arginase and their effect on hypoxiainduced osteosarcoma cell proliferation we used BEC and NOHA. We found that BEC decreased hypoxic urea production in SaOS-2 cells by $79 \pm 6 \%(\mathrm{p}<0.05)$ and that NOHA decreased hypoxic urea production in SaOS-2 cells by $72 \pm 5 \%(\mathrm{p}<0.05)$. SaOS- 2 cells were treated with $100 \mu \mathrm{M}$ BEC or vehicle and incubated in hypoxia or normoxia. The hypoxia- 


\section{Cellular Physiology Cell Physiol Biochem 2016;39:802-813 and Biochemistry \begin{tabular}{l|l} 
DOI: 10.1159/000447790 & (c) 2016 The Author(s). Published by S. Karger AG, Basel \\
www.karger.com/cpb
\end{tabular} \\ Setty et al.: Arginase and Osteosarcoma Cells}

Fig. 6. Transfection with siRNA against arginase II had no effect on arginase I expression. Sa-OS2 cells were not transfected (C), transfected with scramble (SC) or argII siRNA (siR), and incubated for 48 hours in either $21 \% \mathrm{O}, 5 \% \mathrm{CO}_{2}$ (normoxia) or $1 \% 0,5 \% \mathrm{CO}_{2}{ }^{2}$ (hypoxia). Protein was harvested for western blot analysis of arginase II, arginase I and $\beta$-actin.

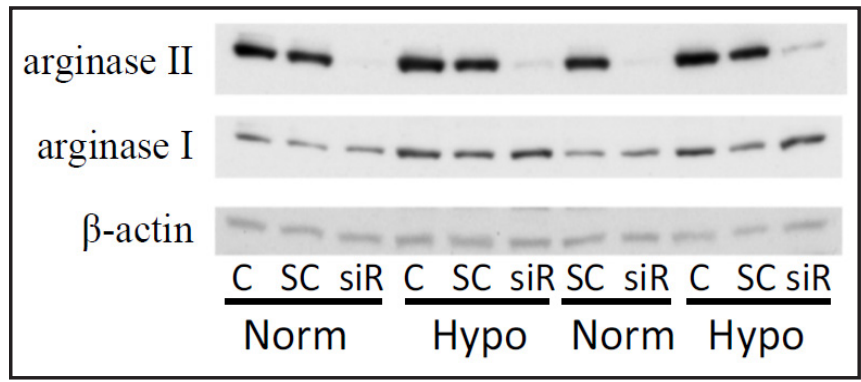

induced increase in cell proliferation was prevented by the addition of BEC to the medium (Fig. 4A). SaOS-2 cells were treated with $10 \mu \mathrm{M}$ NOHA or vehicle and incubated in hypoxia or normoxia. The hypoxia-induced increase in cell proliferation was prevented by the addition of NOHA to the medium (Fig. 4B). The studies were repeated in OS-17 cells with similar results (Fig. 4C for BEC, Fig. 4D for NOHA). These studies support the notion that the effect of the small molecule inhibitors on hypoxia-induced proliferation were through their effects on arginase.

Transfection with Arginase II-small interfering RNA prevented hypoxia-induced cell proliferation

To delineate the role of arginase II in the hypoxia-induced proliferative response of SaOS2 and OS-17 cells, siRNA against arginase II was used. The specific knock-down of arginase II expression by siRNA was confirmed in the SaOS-2 and OS-17 cells by Western blot analysis. The effect of knock-down of arginase II on viable cell numbers was determined in normoxic and hypoxic exposed SaOS-2 and OS-17 cells using trypan blue exclusion. Cells were again seeded at 5,000 per well in a 6-well plate, transfected for 24 hours and then incubated in normoxia or hypoxia for 48 hours. In both SaOS-2 (Fig. 5A) and OS-17 (Fig. 5C) cells arginase II siRNA effectively knocked down arginase II protein levels and prevented hypoxia-induced arginase II protein expression, while scramble siRNA had no effect on either normoxic or hypoxic arginase II protein levels. Arginase II siRNA completely prevented the hypoxiainduced increase in viable cell numbers in the SaOS-2 cells, while scramble siRNA had no effect on the hypoxia-induced increase in viable SaOS-2 cell number (Fig. 5B). Similarly, arginase II siRNA completely prevented the hypoxia-induced increase in viable OS-17 cell numbers, while scramble siRNA had little effect on the hypoxia-induced increase in viable OS-17 cell numbers (Fig. 5D). There were no significant differences seen between normoxic control and normoxic arginase II-siRNA transfected cells, or between normoxic scramble siRNA and normoxic arginase II-siRNA transfected cells (Fig. 5B \& 5D).

Transfection with Arginase II-small interfering RNA had no effect on arginase I

The effect of transfection with arginase II siRNA on arginase I was also studied. Sa-OS2 cells were seeded into 6-well plates 24 hours before transfection to reach $70 \%$ confluence at the time of transfection. Sa-OS2 cells were either not transfected or transfected with scramble siRNA or argII siRNA for 24 hours. The media was then replaced and cells were placed in either normoxia or hypoxia 48 hours before harvesting protein for western blot analysis. As previously described, increased expression of arginase I was noted under hypoxic conditions but there were no demonstrated change after transfection with arginase II siRNA. On the other hand, arginase II expression was decreased after transfection with arginase II siRNA under both normoxic and hypoxic conditions (Fig. 6).

\section{Heat map}

Xenograft models of various malignancies, both solid tumors and hematopoietic tumors, available through the Pediatric Preclinical Testing Program, were evaluated for the presence of arginase and its upstream receptor, EGFR. We found that the 7 available osteosarcoma xenografts examined (OS-1, OS-2, OS-9, OS17, OS-30, OS-31 and OS-33) had consistently high 


\section{Cellular Physiology Cell Physiol Biochem 2016;39:802-813 and Biochemistry Published online: August 01, $2016 \quad \begin{aligned} & \text { DOI: } 2016 \text { The Author(s). Published by S. Karger AG, Basel } \\ & \text { www.karger.com/cpb }\end{aligned}$

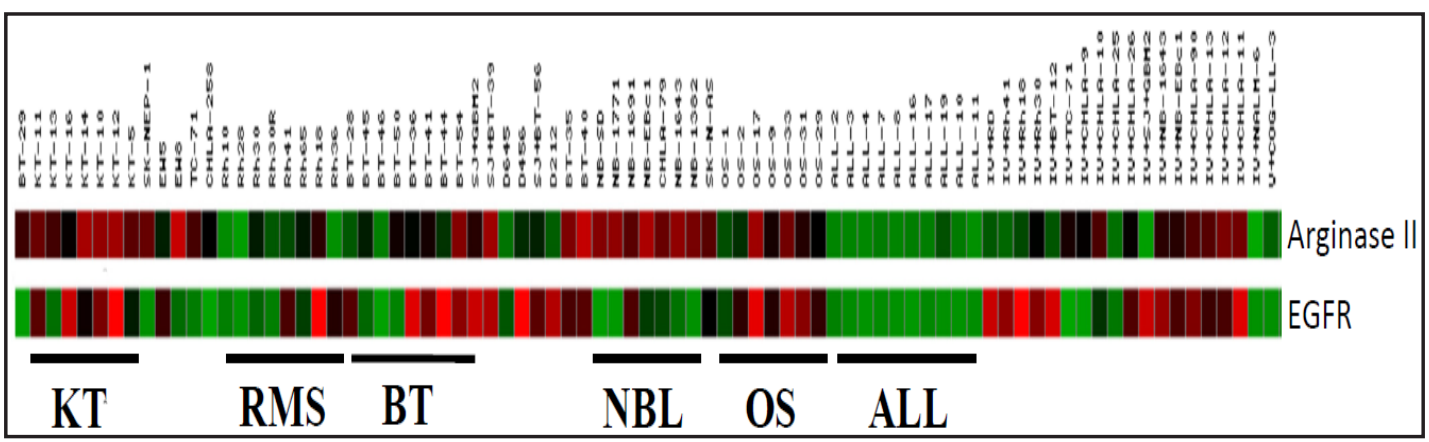

Fig. 7. The colored heat map depicts expression of arginase II and epidermal growth factor receptor (EGFR) in various malignancies. The red and black bars indicate a high level of expression and are demonstrated in osteosarcoma cells (OS), kidney tumor cells (KT), neuroblastoma (NBL) and most brain tumor cells (BT), while the green bars indicate low levels of expression as seen in acute lymphocytic leukemia (ALL) and rhabdomyosarcoma (RMS).

levels of expression of arginase II when compared to other malignancies (Fig. 7). Interestingly, the xenografts from rhabdomyosarcoma (RMS) and acute lymphoblastic leukemia (ALL) had little expression of arginase II, while some of the other solid tumors such as kidney tumors (KT), brain tumors (BT) and neuroblastoma (NBL) showed high levels of arginase II expression.

\section{Discussion}

The major findings of our study were that in two different human osteosarcoma cell lines: 1) hypoxia increased arginase II mRNA and protein levels, 2) hypoxia did not change arginase II mRNA or protein stability, 3) hypoxia had little effect on arginase I protein levels, 4) hypoxia resulted in greater viable cell numbers, 5) hypoxia-induced increases in viable cell number was prevented by DFMO, BEC, and NOHA, and 6) siRNA targeting arginase II prevented hypoxia-induced cell proliferation. These data support our hypothesis that hypoxia results in proliferation of osteosarcoma cells that depends on arginase II induction.

To our knowledge, this is the first report of the central role of arginase II in hypoxiainduced proliferation in osteosarcoma cells. A central role for arginine, the substrate for arginase, in the multi-step processes resulting in cancer have been described [19]. Furthermore, an essential role for arginine has been shown for multiple cancer cell lines, where depriving cancer cells of arginine resulted in cell death [20]. Goldstein et al. [21] recently described that in immunodeficient mice, an orthotopic xenograft of osteosarcoma expressed arginase I. We found that both SaOS-2 and OS-17 cells expressed arginase I but that hypoxia did not result in significant up-regulation or down-regulation of arginase I protein levels. On the other hand, arginase II gene and protein expression were both up-regulated in SaOS-2 and OS-17 cells by exposure to hypoxia. These data suggest that it is arginase II that is the hypoxia-inducible isoform in osteosarcoma. Furthermore, our results demonstrate the central role of arginase II in hypoxia-induced osteosarcoma cell proliferation. Recently it has been reported in patients with pancreatic cancer that arginase II was found in cancerassociated fibroblasts and that the presence of arginase II indicated tissue hypoxia [22]. These findings are also consistent with previous findings in human pulmonary endothelial cells [7] and human pulmonary artery smooth muscle cells [6] wherein hypoxia resulted in up-regulation of arginase II protein expression and was required for hypoxia-induced proliferation. In macrophages from rats and mice it has been shown that hypoxia induces arginase I protein expression and interestingly suppresses arginase II protein expression [23]. Thus, it may be that the arginase isoform up-regulated by hypoxia is cell-type dependent. However, clearly in SaOS-2 and OS-17 cells arginase II is the predominant arginase isoform up-regulated by hypoxia. 
Recently, the tumor microenvironment has been studied as a key player for modulation of metabolism, tumor growth, progression, and metastasis to distant sites [24, 25]. At a molecular level, hypoxia induced S-phase arrest has been shown to be associated with inhibition of DNA replication in both the initiation and elongation phases. Chronic hypoxia exposure prevents replication restart after re-oxygenation. However, acutely exposed cells are still able to restart replication despite the presence of an active checkpoint response and re-oxygenation-induced DNA damage and thus increase genomic instability and likely cause more aggressive phenotypes [26]. Clearly, hypoxia-induced proliferation in the SaOS-2 and OS-17 cells suggests that at least some types of osteosarcoma respond to hypoxia with increased cellular proliferation. We speculate that hypoxia-induced arginase II expression and proliferation may be markers for more aggressive, less chemotherapy responsive, osteosarcomas. Further studies are needed to determine if arginase II may be a marker of poor therapeutic response in osteosarcoma.

The putative arginase inhibitors DFMO, BEC, and NOHA, as well as siRNA-mediated arginase II knock-down prevented hypoxia-induced cellular proliferation in both SaOS-2 and OS-17 cells. This finding is consistent with recent work in human lung endothelial cells, where arginase inhibition using small molecule inhibitors completely prevented hypoxiainduced cellular proliferation [7]. Recently, Krotova et al. [27] found that silencing HIF-2 in lung endothelial cells prevented hypoxia-induced arginase II expression. Similarly, Takeda et al. [28] found that in thioglycollate-elicited mouse peritoneal macrophages arginase II was induced by Th2 mediated HIF-2 activation. The presence of increased HIF-1 has been associated with metastasis and poor overall survival. It may be that hypoxia-induced arginase II expression involves HIF activation, although further studies will be needed to delineate the exact intracellular pathways that lead to arginase II induction. However, the possibility that HIF may be involved is of interest given the finding that overexpression of HIF-1 and HIF-2 are clinically associated with osteosarcoma [29].

It has also been shown that T-cell function can be suppressed by human granulocyte arginase, the arginase released can result in very high arginase activity locally and result in suppression of T-cell proliferation and cytokine synthesis [30]. A similar regulation of human NK cells by arginase released from granulocytes has also been reported [31]. Furthermore, it has recently been shown that meschymal stromal cells transform neutrophils into an immunosuppressive phenotype in part by inducing arginase expression and activity [32,33]. Thus, arginase by consuming arginine locally can have immunosuppressive effects, which may promote tumor cell survival [34-36]. Although our results demonstrate a clear role for arginase II in hypoxic proliferation of osteosarcoma cells, it may be that arginase-induced immunosuppression is another potential mechanism involved in osteosarcoma progression in vivo, and future studies should examine this potential mechanism.

In conclusion, we found that arginase II gene and protein expression were increased in two osteosarcoma cell lines, SaOS-2 and OS-17, exposed to hypoxia. Exposure to hypoxia was associated with increased cellular proliferation as evidenced by an increase in viable cell number in these osteosarcoma cell lines. Both pharmacological inhibition of arginase and siRNA targeting arginase II completely prevented the hypoxia-induced proliferative response in SaOS-2 and OS-17 cells. These data strongly suggest that arginase II is required for hypoxia-induced proliferation of osteosarcoma cells. The analysis of a wide array of pediatric malignancies demonstrates consistently high expression of arginase II in the currently available osteosarcoma xenografts. These data emphasizes the importance of understanding the role of arginase II in proliferation of osteosarcoma cells, in order to better understand the biology of the tumor and to develop much needed novel therapeutic agents to improve the survival from this otherwise devastating disease.

\section{Disclosure Statement}

The authors have nothing to disclose.

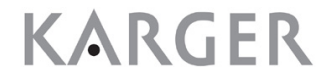




\section{Cellular Physiology Cell Physiol Biochem 2016;39:802-813

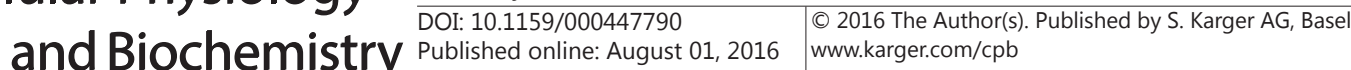 \\ Setty et al.: Arginase and Osteosarcoma Cells}

\section{References}

1 Isakoff MS, Bielack SS, Meltzer P, Gorlick R: Osteosarcoma: Current treatment and a collaborative pathway to success. J Clin Oncol 2015;33:3029-3035.

2 Geller DS, Gorlick R: Osteosarcoma: a review of diagnosis, management, and treatment strategies. Clin Adv Hematol Oncol 2010;8:705-718.

3 Feitelson MA, Arzumanyan A, Kulathinal RJ, Blain SW, Holcombe RF, Mahajna J, Marino M, MartinezChantar ML, Nawroth R, Sanchez-Garcia I, Sharma D, Saxena NK, Singh N, Vlachostergios PJ, Guo S, Honoki K, Fujii H, Georgakilas AG, Bilsland A, Amedei A, Niccolai E, Amin A, Ashraf SS, Boosani CS, Guha G, Ciriolo MR, Aquilano K, Chen S, Mohammed SI, Azmi AS, Bhakta D, Halicka D, Keith WN, Nowsheen S: Sustained proliferation in cancer: Mechanisms and novel therapeutic targets. Semin Cancer Biol 2015;35:S25-S54.

4 Vaupel P, Mayer A: Hypoxia in cancer: significance and impact on clinical outcome. Cancer Metastasis Rev 2007;26:225-239.

5 Siemann DW, Horsman MR: Modulation of the tumor vasculature and oxygenation to improve therapy. Pharmacol Ther 2015;153:107-124.

6 Chen B, Calvert AE, Cui H, Nelin LD: Hypoxia promotes human pulmonary artery smooth muscle cell proliferation through induction of arginase. Am J Physiol Lung Cell Mol Physiol 2009;297:L1151-L1159.

7 Toby IT, Chicoine LG, Cui H, Chen B, Nelin LD: Hypoxia-induced proliferation of human pulmonary microvascular endothelial cells depends on epidermal growth factor receptor tyrosine kinase activation. Am J Physiol Lung Cell Mol Physiol 2010;298:L600-L606.

8 Cladwell RB, Toque HA, Narayanan SP, Caldwell RW: Arginase: an old enzyme with new tricks. Trends Pharmacol Sci 2015;36:395-405.

9 Nelin LD, Stenger MR, Malleske DT, Chicoine LG: Vascular arginase and hypertension. Curr Hypertension Rev 2007;3:242-249.

10 Durante W, Johnson FK, Johnson RA: Arginase: a critical regulator of nitric oxide synthesis and vascular function. Clin Exp Pharmacol Physiol 2007;34:906-911.

11 Agostinelli E, Marques MP, Calheiros R, Gil FP, Tempera G, Vicenconte N, Battaglia V, Grancara S, Toninello A: Polyamines: fundamental characters in chemistry and biology. Amino Acids 2010;38:393-403.

12 Li H, Meininger CJ, Kelly KA, Hawker JR, Morris SM, Wu G: Activities of arginase I and II are limiting for endothelial cell proliferation. Am J Physiol Regul Integr Comp Physiol 2002;282:R64-R69.

13 Gonzalez GG, Byus CV: Effect of dietary arginine restriction upon ornithine and polyamine metabolism during two-stage epidermal carcinogenesis in the mouse. Cancer Res 1991;51:2932-2939.

14 Jin Y, Liu Y, Nelin LD: Extracellular signal-regulated kinase mediates expression of arginase II but not inducible nitric-oxide synthase in lipopolysaccharide-stimulated macrophages. J Biol Chem 2015;290:2099-2111.

15 Ignarro LJ, Buga CM, Wei LH, Bauer PM, Wu G, del Soldato P: Role of the arginine-nitric oxide pathway in the regulation of vascular smooth muscle cell proliferation. Proc Natl Acad Sci USA 2001;98:4202-4208.

16 Kedia GT, Sonnenberg JE, Kuczyk MA, Uckert S: Arginase enzymes in the human prostrate: expression of arginase isoforms and effects of arginase inhibitors on isolated human prostrate tissue. BJU Int 2012;110:E1196-1201.

17 Wang W, Hein TW, Zhang C, Zawieja DC, Liao JC, Kuo L: Oxidized low-density lipoprotein inhibits nitric oxide-mediated coronary arteriolar dilation by up-regulating endothelial arginase I. Microcirculation 2011;18:36-45.

18 Livak KJ, Schmittgen TD: Analysis of relative gene expression data using real-time quantitative PCR and the 2(-Delta Delta C(T)) Method. Methods 2001;25:402-408.

19 Stechmiller JK, Childress B, Porter T: Arginine immunonutrition in critically ill patients: a clinical dilemma. Am J Crit Care 2004;13:17-23.

20 Scott L, Lamb J, Smith S, Wheatley DN: Single amino acid (arginine) deprivation: rapid and selective death of cultured transformed and malignant cells. Br J Cancer 2000;83:800-810.

21 Goldstein SD, Hayashi M, Albert CM, Jackson KW, Loeb DM: An orthotopic xenograft model with survival hindlimb amputation allows investigation of the effect of tumor microenvironment on sarcoma metastasis. Clin Exp Metastasis 2015;32:703-715. 


\section{Cellular Physiology Cell Physiol Biochem 2016;39:802-813 \begin{tabular}{l|l|l} 
DOI: 10.1159/000447790 & Ond 2016 The Author(s). Published by S. Karger AG, Basel \\
www.karger.com/cpb
\end{tabular} \\ Setty et al.: Arginase and Osteosarcoma Cells}

22 Ino Y, Yamazaki-Itoh R, Oguro S, Shimada K, Kosuge T, Zavada J, Kanai Y, Hiraoka N: Arginase II expressed in cancer-associated fibroblasts indicates tissue hypoxia and predicts poor outcome in patients with pancreatic cancer. PLoS One 2013;8:e55146.

23 Louis CA, Reichner JS, Henry WL, Mastrofrancesco B, Gotoh T, Mori M, Albina JE: Distinct arginase isoforms expressed in primary and transformed macrophages: regulation by oxygen tension. Am J Physiol 1998;274:R775-R782.

24 Weinberg, RA: Coevolution in the tumor microenvironment. Nat Genet 2008;40:494-495.

25 Vaupel P: Metabolic microenvironment of tumor cells: a key factor in malignant progression. Exp Oncol 2010;32:125-127.

26 Pires IM, Bencokova Z, Milani M, Folkes LK, Li JL, Stratford MR, Harris AL, Hammond EM: Effects of acute versus chronic hypoxia on DNA damage responses and genomic instability. Cancer Res 2010;70:925-935.

27 Krotova K, Patel JM, Block ER, Zharikov S: Hypoxic upregulation of arginase II in human lung endothelial cells. Am J Physiol Cell Physiol 2010;299:C1541-C1548.

28 Takeda N, O’Dea EL, Doedens A, Kim JW, Weidemann A, Stockmann C, Asagiri M, Simon MC, Hoffmann A, Johnson RS: Differential activation and antagonistic function of HIF- $\alpha$ isoforms in macrophages are essential for NO homeostasis. Genes Dev 2010;24:491-501.

29 Rankin EB, Giaccia AJ, Schipani E: A central role for hypoxic signaling in cartilage, bone, and hematopoiesis. Curr Osteoporos Rep 2011;9:46-52.

30 Munder M, Schneider H, Luckner C, Giese T, Langhans CD, Fuentes JM, Kropf P, Mueller I, Kolb A, Modolell M, Ho AD: Suppression of T-cell function by human granulocyte arginase. Blood 2006;108:1627-1634.

31 Oberlies J, Watzl C, Giese T, Luckner C, Kropf P, Müller I, Ho AD, Munder M: Regulation of NK cell function by human granulocyte arginase. J Immunol 2009;182:5259-5267.

32 Wang YG, Xiong X, Chen ZY, Liu KL, Yang JH, Wen Q, Wu FQ, Hu XF, Peng YD, Wu JJ, Lian YT, Zhang WC, Cheng LX: Expansion of myeloid-derived suppressor cells in patients with acute coronary syndrome. Cell Physiol Biochem 2015;35:292-304.

33 Hu X, Zhou Y, Dong K, Sun Z, Zhao D, Wang W, Yu G, Liu W, Xu G, Han Z, Feng X: Programming of the development of tumor-promoting neutrophils by mesenchymal stromal cells. Cell Physiol Biochem 2014;33:1802-1814.

34 Gielen PR, Schulte BM, Kers-Rebel ED, Verrijp K, Bossman SA, Ter Laan M, Wesseling P, Adema GJ: Elevated levels of polymorphonuclear myeloid-derived suppressor cells in patients with glioblastoma highly express S100A8/9 and arginase and suppress T cell function. Neuro Oncol DOI:10.1093/neuonc/now034.

35 Mussai F, Egan S, Hunter S, Webber H, Fisher J, Wheat R, McConville C, Sbirkov Y, Wheeler K, Bendle G, Petrie K, Anderson J, Chesler L, De Santo C: Neuroblastoma Arginase Activity Creates an Immunosuppressive Microenvironment That Impairs Autologous and Engineered Immunity. Cancer Res 2015;75:3043-3053.

36 Fletcher M, Ramirez ME, Sierra RA, Raber P, Thevenot P, Al-Khami AA, Sanchez-Pino D, Hernandez C, Wyczechowska DD, Ochoa AC, Rodriguez PC: l-Arginine depletion blunts antitumor T-cell responses by inducing myeloid-derived suppressor cells. Cancer Res 2015;75:275-283. 